\title{
COMPARATIVE STUDY OF EFFICACY AND SAFETY OF AZITHROMYCIN ALONE AND IN COMBINATION WITH PROBIOTIC IN THE TREATMENT OF IMPETIGO IN CHILDREN
}

\author{
DHARANI SUDHA G. ${ }^{1}$, NIRMALA P. ${ }^{2}$, RAMANATHAN R. ${ }^{3}$, VANITHA SAMUEL ${ }^{4}$ \\ Department of Pharmacology, Rajah Muthiah Medical College, Annamalai University, Chidambaram, Tamil Nadu, India \\ Email: dharanisudha.b@gmail.com
}

Received: 20 Aug 2017, Revised and Accepted: 13 Oct 2017

\begin{abstract}
Objective: Impetigo is a superficial infection of the skin that involves only the epidermis. It affects mostly children, usually on exposed areas of the body (eg. The face and the legs). Staphylococcus aureus is the most important causative organism. Streptococcus pyogenes (i.e.) group A betahemolytic streptococcus) causes fewer cases, either alone or in combination with S. aureus. The objective of this study is to find out the efficacy and safety of azithromycin alone and in combination with probiotic among children suffering from impetigo.

Methods: This prospective, randomized, single-blinded interventional study was conducted for a period of 6 mo in pediatric OPD and dermatology OPD in Rajah Muthiah Medical College and Hospital. A total of 100 patients, randomly divided into two groups with 50 patients in each group. Group, I patients treated with Azithromycin $10 \mathrm{mg} / \mathrm{kg} / \mathrm{d}$ for $5 \mathrm{~d}$. Group II patients treated with Azithromycin 10 mg/kg/d for $5 \mathrm{~d}$ with probiotic (50 million spores of Lactobacillus sporegens, Streptococcus faecalis 30 million spores, clostridium butyricum 2 million spores,
\end{abstract} Bacillus mesentericus 1 million spores) twice daily for $5 \mathrm{ds}$.

Results: Reduction in a number of lesions and wound area, clinical response were highly significant in Azithromycin with the probiotic-treated group.

Conclusion: In this study, probiotic bacteria may counteract the inflammatory process beyond the intestinal milieu. The results of this study indicate that Azithromycin with probiotic is effective in the treatment of impetigo.

Keywords: Impetigo, Azithromycin, Probiotic, Staphylococcus aureus, Streptococcus pyogenes

(c) 2017 The Authors. Published by Innovare Academic Sciences Pvt Ltd. This is an open access article under the CC BY license (http://creativecommons.org/licenses/by/4.0/] DOI: http://dx.doi.org/10.22159/ijcpr.2017v9i6.23429

\section{INTRODUCTION}

Approximately one in five children who present for primary pediatric health care have a skin complaint, and among them, bacterial infections are the single most common diagnosis, accounting for up to $17 \%$ of visits for skin-related problems [1-2] Impetigo is a highly contagious infection of the superficial epidermis that most often affects children two to five years of age, although it can occur in any age group. Among children, impetigo is the most common bacterial skin infection and the third most common skin disease overall, behind dermatitis and viral warts [3-4]. There are two types of impetigo: nonbullous (i.e. impetigo contagious of Tilbury Fox) and bullous type. Impetigo is typically classified as primary or secondary. Primary impetigo occurs following a bacterial invasion of previously normal skin. In secondary impetigo, infection occurs secondary to some other underlying skin disease that disrupts the function of skin barrier such as atopic eczema, hence the term impetiginized eczema. Most superficial skin infection due to Staphylococcus aureus or Streptococcus pyogenes can be treated effectively with local wound care and oral antibiotics. Azithromycin concentrates highly in tissues (10-100 fold, compared to 5-10 fold for erythromycin), within macrophages and neutrophils (up to 26 fold greater than erythromycin), [5] and may be transported within phagocytes to areas of inflammation. Due to its slow release from tissues, azithromycin can be dosed once daily for a relatively short period of time ( $5 \mathrm{~d}$ ) for the treatment of skin and skin structure infections. Azithromycin has a lower incidence of gastrointestinal side effects, improved pharmacokinetic properties, and broader in vitro antimicrobial activity and is safe for use in patients with penicillin or sulfonamide allergy. Probiotics are defined as live microbial food ingredient beneficial to health [6] are normal commensal bacteria of the healthy human gut microflora. The most frequently used genera are lactobacilli and bifidobacteria, and the best documented current therapeutic application is in the prevention and treatment of diarrhoeal disease. Probiotic may counteract inflammatory response beyond the intestinal milieu [7].
Numerous studies have evaluated the potential efficacy of probiotic in the prevention and treatment of allergic diseases in general, and of atopic eczema in particular. Clinical improvement in atopic eczema following probiotic supplementation has been reported in some studies and the therapeutic effect of probiotic on atopic dermatitis seems to be encouraging. In secondary impetigo, infection occurs secondary to atopic eczema. Probiotic showed clinical improvement in atopic eczema, based on updated information, the topic of the administration of probiotic are addressed in the study. So, this study was undertaken to compare the safety and efficacy of azithromycin alone and in a combination of probiotic in the treatment of impetigo in children.

\section{MATERIALS AND METHODS}

This is a prospective, randomized, single blinded interventional study in a subject diagnosed with impetigo conducted for a period of 6 mo from June to November 2016. Patients screening and recruitment were carried out at the out patient Department of Dermatology, Paediatrics in Rajah Muthiah Medical College and Hospital. The study was initiated after obtaining approval from the Rajah Muthiah Medical College Institutional Human Ethics Committee. A total of 100 patients were enrolled in the study. Written informed consent was obtained from either of the parents before participation into the study. They were randomly divided into two groups with 50 patients in each group. Patients diagnosed as impetigo by the pediatrician or dermatologist of either gender in the age group of 1 to $15 \mathrm{y}$ with the number of lesions up to 10 or area of lesions not exceeding $100 \mathrm{~cm}$ sq were included in this study. Immuno-compromised children and children with other bacterial skin infections are excluded from the study. Group I patients was treated with Azithromycin $10 \mathrm{mg} / \mathrm{kg} / \mathrm{d}$ for $5 \mathrm{~d}$. The drug administration was two $\mathrm{h}$ after meals. Group II patients were treated with Azithromycin $10 \mathrm{mg} / \mathrm{kg} / \mathrm{d}$ for $5 \mathrm{~d}$ with probiotic (50 million spores of Lactobacillus sporegens, Streptococcus faecalis 30 million spores, clostridium butyricum 2 million spores, Bacillus mesentericus 1 million spores) twice daily for $5 \mathrm{~d}$. Probiotic was administered two 
$\mathrm{h}$ before meals and Azithromycin were administered two h after meals. Initially, the patients were screened to access their eligibility for this study. As a part of the screening, medical history of the patients was taken, physical examination and clinical examination were done. The patients were monitored two times in the study, once at the baseline, and later at the end of five ds treatment. General physical and systemic examination was done and patients were enquired for the incidence of adverse effects. Wound size area was determined by measuring the greatest length of the wound in two perpendicular dimensions with a standard metric ruler. The two measurements were multiplied together to provide an estimate of the overall wound size. Surrounding erythema was not included in the measurement.

\section{Statistical analysis}

The statistical analysis was carried out with SPSS VER. 16.0 Software. All the data were presented as mean, standard deviation, and percentage of efficacies. Chi-square and paired ' $t$ ' test is used to evaluate the statistical significance between two drugs. In this study, $(\mathrm{P}<0.05)$ is considered as significant.

Table 1: Demographic characteristics of impetigo children

\begin{tabular}{llll}
\hline & & Group I (Azithromycin) \% & Group II (Azithromycin with Probiotic) \% \\
\hline Age & $1-5 \mathrm{y}$ & $23(46 \%)$ & $29(58 \%)$ \\
& $6-10 \mathrm{y}$ & $21(42 \%)$ & $16(32 \%)$ \\
\multirow{3}{*}{ Gender } & $11-15 \mathrm{y}$ & $6(12 \%)$ & $5(10 \%)$ \\
& Male & $26(52.0 \%)$ & $28(56.0 \%)$ \\
& Female & $24(48.0 \%)$ & $22(44.0 \%)$ \\
\hline
\end{tabular}

\section{RESULTS}

\section{Legend: 1}

Out of 100 children, $26(52 \%)$ were male and $24(48 \%)$ were female in group I. In group I, 28(56\%) were male and 22(44\%) were female. Maximum children were between the age group of $1-5$ y $(46 \%$ in group I and 58\% in group II). As per table 1, the incidence of impetigo was more common among male children compared to female.

\section{Legend: 2}

The above table shows paired ' $t$ ' test is carried out to test the number of lesions and wound area between the study group. The number of lesions in group I was reduced from the mean value of $5.82+1.88$ on the $1^{\text {st }} d$ to $1.68+1.03$ on the $5^{\text {th }} \mathrm{d}$. In group II the number of lesions was reduced from the mean value of $4.26+0.80$ on the $1^{\text {st }} \mathrm{d}$ to
$0.14+0.70$ on the $5^{\text {th }} \mathrm{d}$. The mean wound area of group I was $3.17+0.71$ and it reduced to a mean value of $1.10+0.42$. In group II from the initial mean value of $3.40+0.91$ was found to be reduced to $0.34+1.19$. In both the parameters $p$ value $<0.001$ confirms that there is highly significant difference has been noted in the mean value between two groups at $5^{\text {th }} d$.

Legend: 3

In Group I, 8 out of 50 patients were completely cured (absence of lesions) and 42 patients are not cured (presence of lesions). In Group II, 48 out of 50 patients were completely cured (absence of lesions) and 2 patients are not cured (presence of lesions). Azithromycin with probiotic is showing $95 \%$ of clinical efficacy compared to $16 \%$ clinical efficacy of Azithromycin alone. There is the highly statistically significant difference between two groups, with $\mathrm{p}<0.001$.

Table 2: Effect of azithromycin alone and the co-administration of azithromycin with probiotic on the number of lesions and mean wound area

\begin{tabular}{llllll}
\hline & & $\begin{array}{l}\text { Group I (Azithromycin) } \\
\text { (mean } \pm \text { SD) }\end{array}$ & $\begin{array}{l}\text { Group II (Azithromycin with Probiotic) } \\
\text { (mean } \pm \text { SD) }\end{array}$ & Paired 't' test & p-value \\
\hline No of lesions & No of lesions Base line & $5.8200 \pm 1.88105$ & $4.2600 \pm 0.80331$ & 5.393 & $<.692$ \\
Wound Area & $\begin{array}{l}\text { No of lesions 5th D } \\
\text { Wound area }\end{array}$ & $1.6800 \pm 1.03884$ & $0.1400 \pm 0.70015$ & 1.412 & $<0.001$ \\
& $\begin{array}{l}\text { (cm square) Base line } \\
\text { Wound area }\end{array}$ & $3.1700 \pm 0.71976$ & $3.4020 \pm 0.91238$ & 4.239 & \\
\hline & & & $0.3480 \pm 1.19578$ & & \\
\hline
\end{tabular}

Table 3: Clinical response and clinical efficacy in both groups

\begin{tabular}{llll}
\hline Lesions & Group I (Azithromycin) & Group II (Azithromycin with Probiotic) & P value \\
\hline Cured (Absence of lesions) & 8 & 48 \\
Not cured (Presence of lesions) & 42 & 2 \\
Efficacy (\%) & $16(\%)$ & $95.83(\%)$ \\
\hline
\end{tabular}

p-value $<0.001$ is highly significant, calculated using the chi-square test

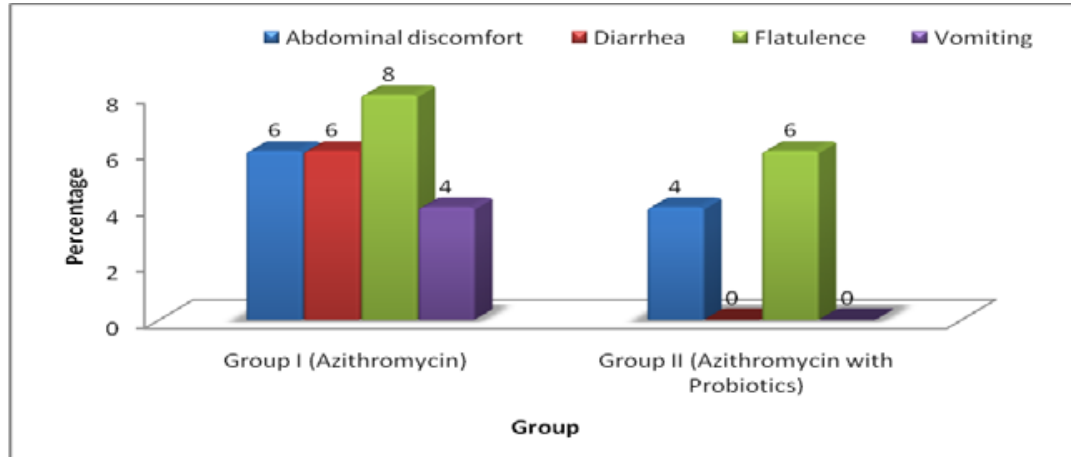

Fig. 1: Incidence of adverse events in study groups 


\section{Legend: 4}

The above fig. shows all the adverse events observed in both groups were mild and these resolved within $24 \mathrm{~h}$ after they appeared. In Group I, 12 patients with adverse events are reported and 5 patients with adverse events are reported in Group II. Most common adverse

\section{Azithromycin alone}

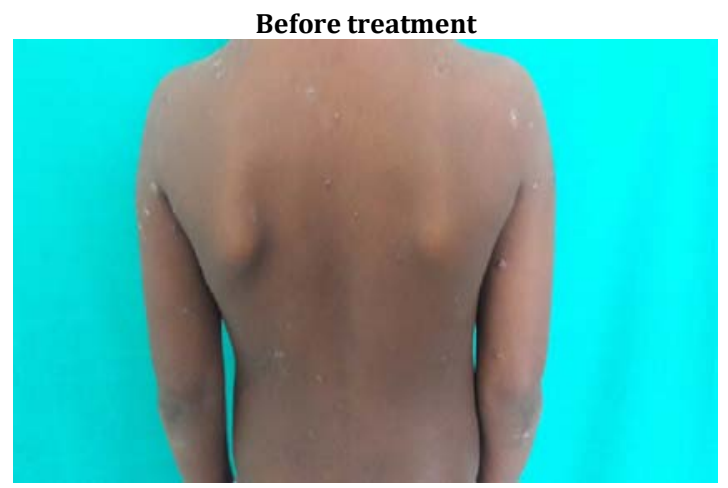

Azithromycin with probiotic

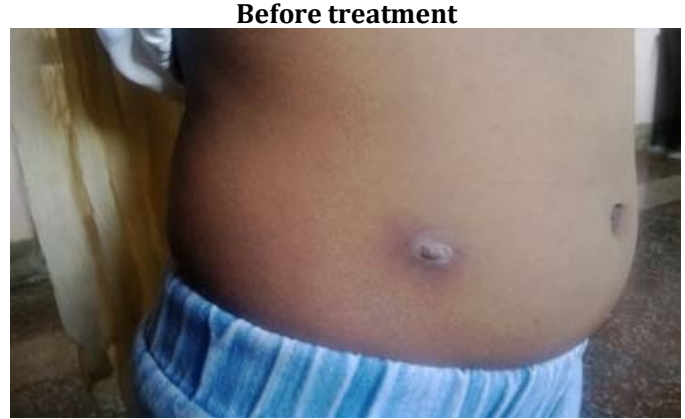

\section{DISCUSSION}

Several studies have also shown that pretreatment with probiotic bacteria can overcome the poor resistance occurring due to alteration of epithelial cell tight junction caused by stress, infection or proinflammatory cytokines. They alter the function of epithelial barrier by influencing the preservation of tight junctions. It has been well established that probiotic may counteract inflammatory response beyond the intestinal milieu [7]. Probiotic may enhance the production of anti-inflammatory cytokines in epithelial cells as well as in monocytes and macrophages. Two bacterial which is most prevalent in the intestine are Bifidobacterium and Lactobacillus. These are normal bacteria with immune function, antimicrobial activity and anti-inflammatory activity. Impetigo is almost always caused by Staphylococcus aureus or streptococci, or by both the organisms. Susceptibility to this infection depends on host immune factors, as well as the virulence of the organisms. There are two clinical types, non-bullous impetigo (impetigo contagiosa) and bullous impetigo. Clinical diagnosis is usually confirmed by gram stain and culture, although this is not usually necessary and clinical signs usually suffice to clinch the diagnosis. A study in the United Kingdom revealed that the annual incidence of impetigo was 2.8 percent in children up to four years of age and 1.6 percent among children five to fifteen years of age [8]. Chopra and Colleagues reported increased incidence in the pediatric age group, attributing it to the poorly developed epidermal barrier in children [9]. In our study, the patients are of the age group of 1 to $15 \mathrm{y}$. The majority of the patients in Group I and Group II are between 1 to 5 y. i.e. $46 \%$ patients in Group I and 58\% patients in Group II, consistent with previous studies. Preschool and young school children are most often affected by impetigo. A higher preponderance for males was noted in our study. In both group I and group II, 52\% and 56\% of event reported is flatulence in both the groups. In Group I flatulence is seen in $8 \%$ patients followed by diarrhoea and abdominal discomfort $6 \%$ each. Vomiting is seen in $4 \%$ of patients. In Group II flatulence is seen in $6 \%$ of patients and $4 \%$ of patients with abdominal discomfort. No adverse events of diarrhoea and vomiting reported.
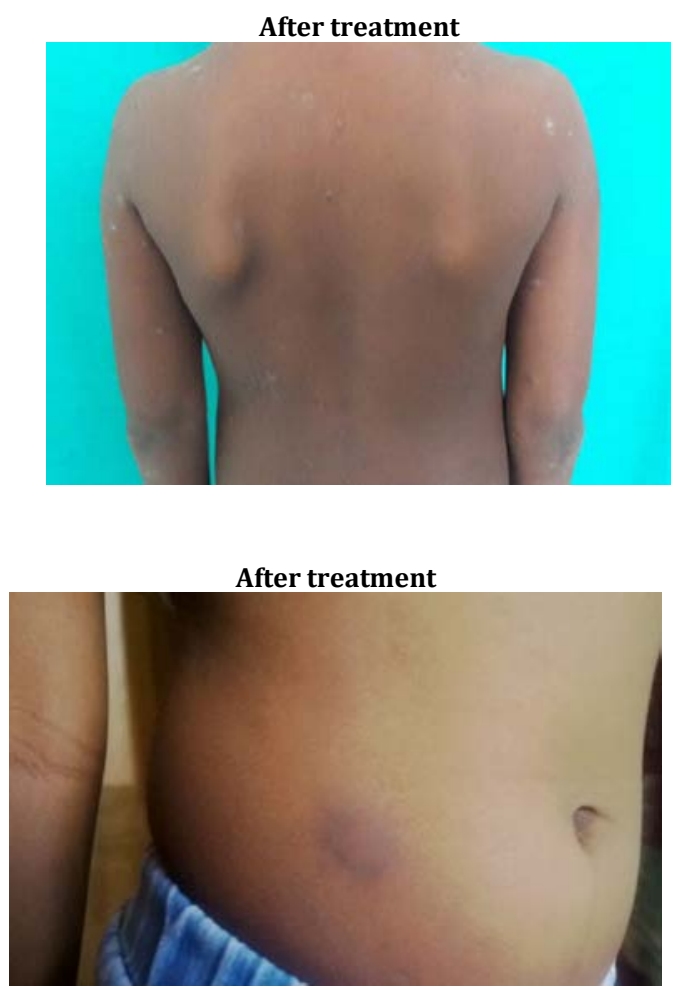

male patients participated respectively. In our study, the number of lesions in Azithromycin group was reduced from the mean value of $5.82+1.88$ on the $1^{\text {st }} \mathrm{d}$ to $1.68+1.03$ on the $5^{\text {th }} \mathrm{d}$. In Azithromycin with the probiotic group, the number of lesions was reduced from the mean value of $4.26+0.80$ on the $1^{\text {st }} d$ to $0.14+0.70$ on the $5^{\text {th }} d$. The mean wound area of Azithromycin group was $3.17+0.71$ and it reduced to a mean value of $1.10+0.42$. In Azithromycin with a probiotic group from the initial mean value of $3.40+0.91$ was found to be reduced to $0.34+1.19$. In impetigo combination of Azithromycin with probiotic was found to be more efficient in controlling Staphylococcus aureus and Streptococcus pyogenes than Azithromycin administered alone. Both groups resulted in a reduction of a number of lesions on the $5^{\text {th }} \mathrm{d}$ of treatment. From our study, it is evident that the reduction in a number of lesions in Azithromycin with probiotic group improved far better than Azithromycin alone. Numerous studies compared various oral antibiotics. Two systematic reviews showed that lactamaseresistant, narrow-spectrum penicillins, broad spectrum penicillins, cephalosporins, and macrolides were, in general, equally effective. Penicillin and amoxicillin were less effective than cephalosporins, cloxacillin, or amoxicillin with clavulanate (Augmentin) [10-11]. Weston et al., (2005) recruited 53 children with moderate to severe atopic dermatitis to evaluate the effect of Lactobacillus fermentum. Results showed that an 8-week supplementation was beneficial in improving extent and severity of atopic dermatitis [12]. In our present study, in Azithromycin group, 8 out of 50 patients were completely cured with nil lesions and 42 patients were not cured and had lesions. In Azithromycin with probiotic group, 48 out of 50 patients are completely cured, without any lesions and 2 patients were not cured and had lesions. Azithromycin with probiotic group showed $95 \%$ of clinical efficacy compared to $16 \%$ clinical efficacy of Azithromycin alone. The statistically significant difference between 
two groups was very high with $\mathrm{p}<0.001$. Guidelines for probiotic in a review for study design, target populations, selection of placebo and probiotic microorganism, duration of follow-up, outcome, and end point measurements, safety assessment and regulatory considerations are proposed by Shane, A. L. et al., (2010). [13]. Most common adverse event reported was flatulence in both the groups. In Azithromycin group, flatulence was seen in $8 \%$ patients followed by diarrhea and abdominal discomfort in $6 \%$. Vomiting occurred in $14 \%$ of patients. In Azithromycin with the probiotic group, flatulence was seen in $6 \%$, of patients and abdominal discomfort in $4 \%$ of patients. Diarrhoea and vomiting were not reported by patients of this group. An imbalance in Th1/Th2 immune response has been related to the pathogenesis of allergic diseases [14]. Probiotic effects also may be mediated via control of the balance between pro and anti-inflammatory cytokines. Impetigo is an infectious disease in which probiotic added as an adjuvant therapy by decreasing the incidence of allergic disease and enhance the immune response to infection. Thereby helping in speedy recovery and healing of the lesion. Our current study proves that addition of probiotic with azithromycin can cure the symptoms of impetigo. It reduced the number of lesions and the area of wound. It improved the clinical picture than that of azithromycin alone group. This may be due to the probioticinduced improvement of immune response or may be due to its antiinflammatory action. Regardless of the extent of the lesion, the effect of probiotic was found to be superior to azithromycin alone.

\section{CONCLUSION}

The result of our study explores a new possibility in the horizon of treatment of impetigo. Since the adverse effects caused by probiotic are minimal and tolerable, it could be further exploited for the treatment of other inflammatory or immune conditions that are refractory to treatment with existing chemotherapeutic agents.

\section{ACKNOWLEDGEMENT}

I am thankful to the Professor and HOD, Department of Pharmacology, Professors of the Department of Pharmacology, Rajah Muthiah Medical College, co-guide from the Department of Paediatrics and co-postgraduates for their inspiration to take up this study and they guided me through each and every step of this Research Work, by giving useful suggestions and made me complete this work successfully.

\section{CONFLICT OF INTERESTS}

Declared none

\section{REFERENCES}

1. Mandell, Douglas, Bennett's. S pyogenic is found in only $20 \%$ of cases, in association with $S$. aureus. Principal Practice Infectious Disease 2010;195:2565-6.

2. George Hudson Findlay. Several 'Species' of impetigo was recognized by Thomas Bateman. Dermatol Bacterial Infection 1985;1:43-4.

3. Brown J, Shriner DL, Schwartz RA, Janniger CK. Impetigo: an update. Int J Dermatol 2003;42:251-5.

4. Sladden MJ, Johnston GA. Common skin infections in children. Br Med J 2004;329:95-9.

5. Foulds G, Shepard RM, Johnson RB. The pharmacokinetics of azithromycin in human serum and tissues. J Antimicrob Chemother 1990;25(Suppl A):73-82.

6. Salminen S, Bouley C, Boutron-Ruault MC. Functional and science and gastrointestinal physiology and function. Br J Nutr 1998;80:S147-71.

7. Isolauri E, Arvola T, Sutas E, Moilanen, Salminen S. Probiotic may counteract inflammatory response beyond the intestinal milieu. Clin Exp Allergy 2000;30:1604-10.

8. George A, Rubin G. A systematic review and meta-analysis of treatments of impetigo. Br J Gen Pract 2003;53:480-7.

9. Chopra A, Puri R, Mital RR, Kantha S, Bhatia R. A clinical and bacteriological study of pyodermas. Indian J Dermatol Venereol Leprol 1994;60:200-2.

10. George A, Rubin G. A systematic review and meta analysis of treatments for impetigo. Br J Gen Pract 2003;53:480-7.

11. Mudd SS, Findlay JS. The cutaneous manifestations and common mimickers of physical child abuse. J Pediatr Health Care 2004;18:123-9.

12. Weston S, Halbert A, Richmond P, Prescott SL. Effects of probiotic on atopic dermatitis: a randomized controlled trials. Arch Dis Child 2005;90:892-7.

13. Shane AL, Cabana MD, Very S, Merenstein D, Hummelen R, Ellis CL, et al. Guide to designing, conducting, publishing and communicating results of clinical studies involving probiotic applications in human participants. Gut Microbes 2010; 1:243-53.

14. Romagnani S, Maggi E, Parronchi P, Macchia D, Piccinni MP, Ricci M. Increased numbers of Th2-like CD4+T cells in target organs and in the allergen-specific repertoire of allergic patients. possible role of IL-4 produced by non-T cells. Int Arch Allergy Appl Immunol 1991;94:133-6. 